\title{
ANÁLISE DO ESTADO DE CONSERVAÇÃO DAS OAES FEDERAIS SITUADAS NA BR-101/SC
}

\author{
ANHAIA, CÍNTIA A. A. L. \\ Eng. Civil \\ DNIT/Engefoto \\ Brasília/DF; Brasil \\ cintializ@engefoto.com.br
}

\author{
CÂMARA, MYRELE Y. F. \\ Eng. Civil \\ DNIT/Strata Engenharia/UnB \\ Brasília/DF; Brasil \\ myrelleyasmine@hotmail.com
}

\author{
SILVA, TALITA E. P. \\ Eng. Civil \\ DNIT/Engefoto \\ Brasília/DF; Brasil \\ talitaevelyn.te@gmail.com
}

\author{
SARKIS, JORGE M. \\ Eng. Civil \\ DNIT/Engefoto \\ Brasília/DF; Brasil \\ talitaevelyn.te@gmail.com
}

\author{
SILVA, PATRÍCIA C. S. \\ Eng. Civil \\ DNIT/Engefoto/UnB/UNIProjeção \\ Brasília/DF; Brasil \\ patriciacandida@gmail.com
}

\author{
SOBRINHO, BRUNNO E. \\ Eng. Civil, MsC. \\ DNIT/Engefoto/UnB \\ Brasília/DF; Brasil \\ brunnosobrinho@engefoto.com.br
}

\author{
VIEIRA, JORDANA F. \\ Eng. Civil \\ DNIT/Engefoto/UnB \\ Brasília/DF; Brasil \\ jordanaferreirav@gmail.com
}

\author{
PINTO JÚNIOR, AYMORÉ V. \\ Eng. Civil \\ DNIT/Engefoto/UnB \\ Brasília/DF; Brasil \\ jordanaferreirav@gmail.com
}

\begin{abstract}
RESUMO
As pontes e viadutos são estruturas de grande importância dentro do sistema de transportes de um país. Para garantir a segurança e a integridade dessas estruturas é necessário realizar inspeções periódicas identificando as principais manifestações patológicas e, consequentemente, avaliando a condição de estabilidade e conservação de cada Obra de Arte Especial (OAE). Dessa forma, este trabalho analisará o estado de conservação das OAEs situadas na BR-101, no estado de Santa Catarina. Para isso, foi quantificado 188 obras nesta região no banco de dados de inspeções de Obras de Arte Especiais (SGO) do Departamento Nacional de Infraestrutura de Transportes (DNIT). A partir dessa quantificação foram verificadas as notas das condições de estabilidade e conservação, e analisada as principais manifestações patológicas existentes. Em vista disso, os resultados obtidos mostraram que a maioria das obras apresentaram notas em que não há sinais de comprometimento da estabilidade da obra, em conformidade com a prescrição normativa da ABNT NBR 9452 (2016) e DNIT 010-PRO (2004). No entanto, foi possível observar que cerca de 10 obras apresentaram notas técnicas iguais a 1 ou 2, que configuram situações em que as obras precisam de inspeções especiais ou mesmo extraordinárias para diagnosticar os defeitos com uma maior precisão, auxiliando no plano de indicações de intervenções dessas obras. Dessa maneira, o artigo mostra grande importância na continuidade das inspeções periódicas para acompanhamento do estado de conservação e estabilidade dessas estruturas.
\end{abstract}

Palavras-chave: Obras de Arte Especiais, Inspeções periódicas, Condição de estabilidade, Condição de conservação.

\begin{abstract}
Bridges are very important structures for the transport system in the country. To ensure the safety and integrity of these structures, periodic inspections are necessary to identify the pathology and, consequently, to evaluate the stability and conservation condition of each Special Engineering Structure. This paper will analyze the conservation status of the Special Engineering Structures located on BR-101, in the state of Santa Catarina. For this, 188 inspections in this region were quantified on the database of the Management System for Special Engineering Structures of the National Department of Infrastructure and Transports (DNIT). From the quantification were verified the notes of the conditions of stability and conservation and analyzed the main pathology manifestations existing. As a result, the results obtained showed that most of the works presented notes that are no signs of compromise the stability of the structure, based on the normative prescriptions of ABNT NBR 9452 (2016) and DNIT 010-PRO (2004). However, it was observed 10 works presented technical notes equal to 1 or 2 , that configure situations in which the works need special or even
\end{abstract}


extraordinary inspections to diagnose the defects with greater precision, helping in the indication of interventions plan for these structures. So, the article shows great importance in the continuity of periodic inspections to monitor the state of conservation and stability of the structures.

Keywords: Special Engineering Structures, Periodic inspections, Stability condition, Conservation condition.

\section{INTRODUÇÃO}

A liberdade de locomoção é acolhida na Constituição Federal em seu Art. $5^{\circ}$, inciso XV. Para assegurar este direito, são utilizados diversos meios de transporte e grandes obras da engenharia. Com o intuito de ajudar a vencer as dificuldades de transposição de relevo, as Obras de Arte Especiais (OAEs), pontes e viadutos, são consideradas importantes obras para essas solicitações.

As OAEs têm uma importância muito grande dentro do contexto de uma rodovia. Neste sentido, dar atenção à conservação dessas estruturas é um meio de manter o fluxo sem interrupções e sem prejudicar diversos níveis que dependem da fluidez do transporte rodoviário, principalmente em termos financeiros. As degradações diversas que esses elementos podem sofrer, de diversos agentes externos, aceleram os processos de deterioração e contribuem para situações críticas, ou numa pior condição, o seu colapso (VITÓRIO, 2002)

Ressalta-se que enquanto as estruturas de obras civis especiais estão aumentando em número, tamanho e longevidade, existe uma crescente preocupação no que tange às relações entre o monitoramento, através de inspeções periódicas, e as intervenções de manutenção ao longo da vida útil dessas obras. Tendo em vista a grande importância e utilidade, as Obras de Arte Especiais estão sendo inspecionadas e estudadas, tornando possível um estudo preventivo para se identificar as manifestações patológicas ainda em sua fase inicial. Com isso, através de uma gestão mais efetiva, será possível o planejamento para a reabilitação dessas obras, evitando riscos eminentes.

Dessa forma, será abordado nesse trabalho o estado de conservação das OAEs federais situadas na BR-101, no estado de Santa Catarina, com o objetivo de detalhar as obras com maior índice de manifestações patológicas, a causa e como isso afeta a malha rodoviária federal.

\section{METODOLOGIA}

O presente trabalho trata das 177 obras que estão distribuídas dentro do estado de Santa Catarina na BR-101, as quais foram inspecionadas em concordância com as prescrições normativas da ABNT NBR 9452 (2016) e da DNIT 010-PRO (2004). Este artigo apresenta os resultados da pesquisa realizada pelo autor, com base nas inspeções realizadas, entre os anos de 2018 e 2019. A localização das Obras de Arte Especiais está apresentada na Figura 1 do mapa a seguir.

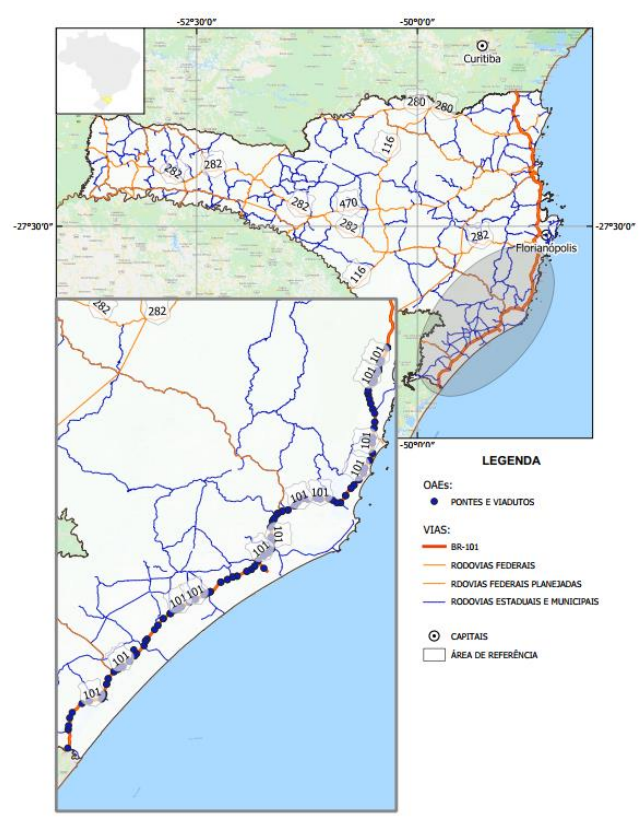

Figura 1: Mapa de localização de OAEs na BR-101/SC 
Nos últimos anos foram tomadas algumas medidas inéditas na história do DNIT, na área de gestão de OAEs, onde foi desenvolvido o Sistema de Gerenciamento de Obras de Arte Especiais (SGO), para melhor gerir estas obras e com estes dados realizar um planejamento adequado, tão importantes para a infraestrutura do país. Este banco de dados do SGO conta com aproximadamente 6.500 obras que estão sob administração federal, destas foram selecionadas 188 OAEs que estão na BR-101/SC.

Nesta pesquisa foram utilizadas as informações disponíveis no Sistema de Gerenciamento de Obras de Arte Especiais (SGO), que apresenta as inspeções segundo a norma DNIT 010/2004-PRO na qual constam as informações relacionadas à época em que foi construída, às características geométricas, aos sistemas estruturais, às condições de conservação e aos danos estruturais, entre outros elementos necessários para avaliar as atuais condições do conjunto das obras estudadas. Estas informações estão divididas em dois tipos, sendo elas as inspeções cadastrais e rotineiras. Sendo a inspeção cadastral como o próprio nome diz a primeira inspeção de uma OAE, ou quando existe elementos que acarretaram alguma mudança na configuração da estrutura. É uma inspeção que deve ser totalmente documentada, com registros fotográficos e coletas de coordenadas geodésicas de latitude e longitude, a qual tem como objetivo fazer um inventário da estrutura e também fornecer informações sobre as condições estruturais. E a segunda é a inspeção rotineira, que são inspeções programadas e seus intervalos não devem exceder o período de 24 meses. Estas inspeções consistem em registrar observações e/ou medições para determinar a condição física e funcional das OAEs.

As notas técnicas finais de cada obra são dadas conforme as prescrições normativas da NBR 9452 (ABNT, 2016) e DNIT 010 - PRO (DNIT, 2004), sendo assim as notas técnicas 5 e 4 são as notas de condição excelente e boa, respectivamente, e não requerem atenção especial nestas obras. As obras de nota técnica 3 necessitam de atenção e, por último, as obras de notas técnicas 2 e 1, que são as obras que tem riscos eminentes, devem ser estudadas, interditadas e, se necessário, restauradas o mais rápido possível. A Figura 2 apresenta de forma resumida as divisões das notas técnicas definidas nas normas.

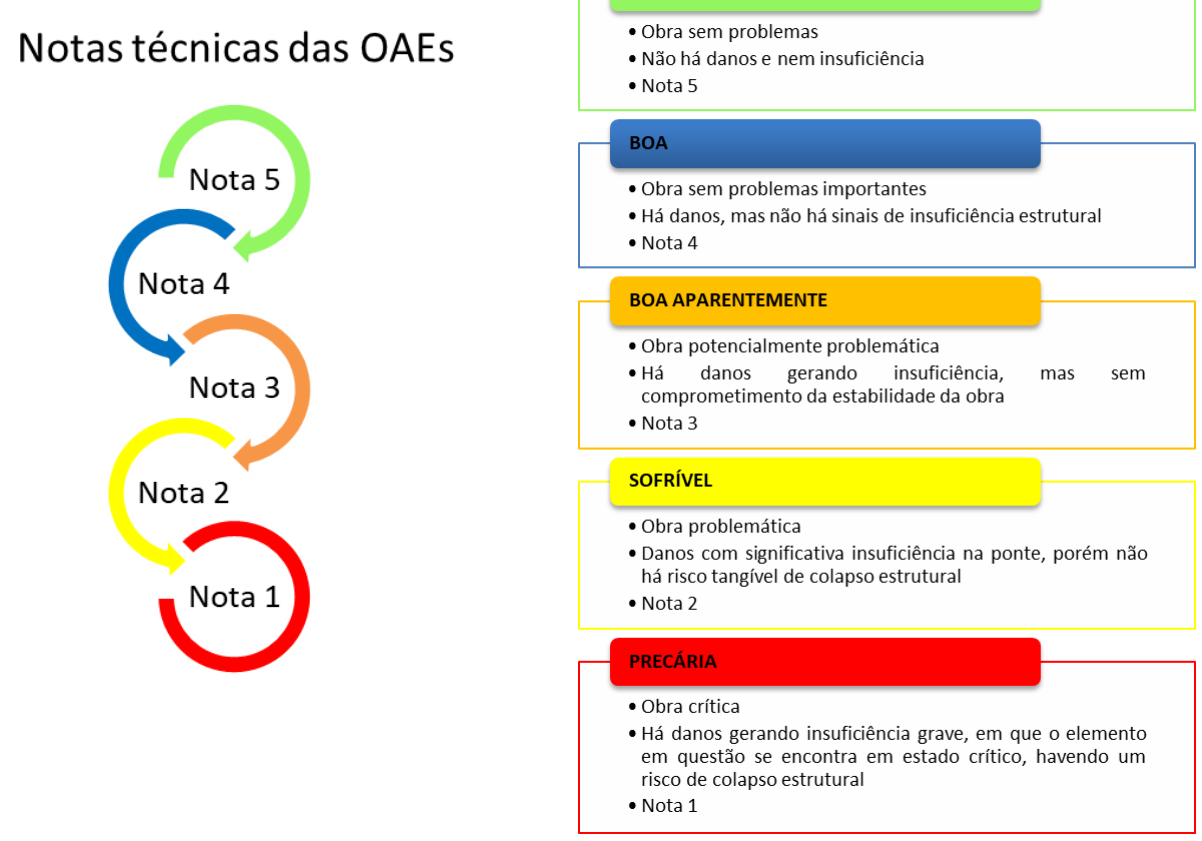

Figura 2: Ranking das notas técnicas para OAEs

Em termos de metodologia, inicialmente foi realizada as pesquisas no SGO das obras da BR-101/SC na primeira etapa, sendo que o primeiro passo consistiu na análise dessas Obras de Arte Especiais contidas nessa rodovia federal. O segundo passo foi delimitar as informações de grande interesse a serem apresentadas no trabalho. Na segunda etapa do trabalho foi realizada a interrelação dos dados e tratamento dos mesmos, e numa terceira etapa apresenta as considerações finais e recomendações. 


\section{ANÁLISE DOS DADOS}

O propósito do estudo é apresentar os tipos de estruturas, bem como as condições destas e suas classificações em conformidade às prescrições das normas ABNT NBR 9452:2016 e DNIT 010-PRO/2004.

Nas inspeções de OAEs no DNIT para alimentar o SGO se usou classificar as OAEs quanto a sua grandeza por faixas de extensão. Assim, foram definidas 5 faixas de extensão como apresentadas na Figura 3, sempre considerando uma margem de $2 \mathrm{~m}$ para mais no limite entre faixas ao fazer a classificação e desprezando elementos de encontro e lajes de aproximação, com outras palavras, considerando a extensão da superestrutura. Uma obra com 22,00 metros de extensão da superestrutura é enquadrada na faixa até 20 metros, outra com 22,01 metros na faixa entre 20 e 60 metros.

Quanto às OAEs da BR-101/SC, estas são consideradas obras de pequeno porte, tendo a maior quantidade de obras com uma extensão na faixa entre 20 e 60 metros, com 101 obras. Nas outras três faixas de extensão superiores, a soma das obras totaliza 48 OAEs distribuídas em cada faixa de extensão, conforme detalhado na Figura 3. Há apenas 4 OAEs

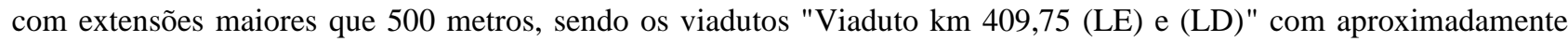
2.300 metros cada um, o "Viaduto km 404,16" com 1.724 metros e a "Ponte Anita Garibaldi" com quase 2.900 metros de comprimento.

\begin{tabular}{ccc}
\hline Extensão das obras & Quantidade & $\%$ \\
\hline até 20 & 28 & $16 \%$ \\
20 a 60 & 101 & $57 \%$ \\
60 a 120 & 24 & $14 \%$ \\
120 a 500 & 20 & $11 \%$ \\
$>500$ & 4 & $2 \%$ \\
\hline SOMA & 177 & \\
\hline
\end{tabular}

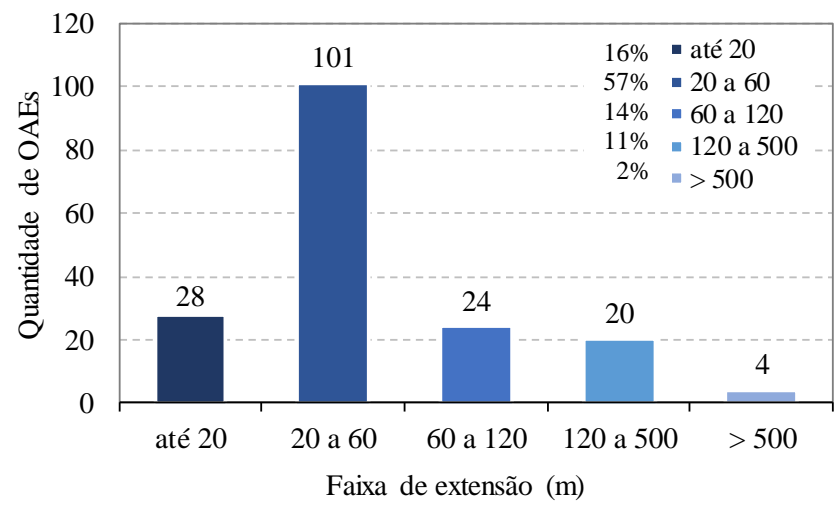

Figura 3: Faixa de extensão das OAEs na BR-101/SC

Dentre as 177 OAEs estudadas, o tipo de estrutura (que considera o elemento principal para vencer os vãos) mais comum foi a viga de concreto protendido, com 108 estruturas, representando $61 \%$ do total. Em outros tipos as quantidades são bem menores, há a presença de vigas de concreto armado em um total de 23 OAEs, a laje de concreto armado em 19 OAEs, e com quantidades bem pequenas, a viga caixão de concreto armado ou protendido com 7 e 11 obras, respectivamente e a estrutura mista, viga metálica e laje de concreto, com 9 obras. A Tabela 1 apresenta estas quantidades e respectivos percentuais em relação ao total de estruturas.

Tabela 1: Relação de OAEs por tipos de estruturas

\begin{tabular}{lcc}
\hline \multicolumn{1}{c}{ Tipo de Estrutura } & Quantidade & Percentual \\
\hline Laje de concreto armado & 19 & 10,7 \\
Mista (viga metal. e laje concreto) & 9 & 5,1 \\
Viga Caixão Concreto Armado & 7 & 4,0 \\
Viga Caixão Concreto Protendido & 11 & 6,2 \\
Viga de concreto armado & 23 & 13,0 \\
Viga de concreto protendido & 108 & 61,0 \\
\hline \multicolumn{1}{c}{ SOMA } & 177 & \\
\hline
\end{tabular}

Relacionando as informações obtidas nas inspeções cadastrais, pode-se concluir que na sua grande maioria, as obras com o sistema estrutural em vigas de concreto protendido possuem menores extensões. Porém, os vãos livres são maiores, justificando o motivo da adoção de estruturas com sistemas de vigas de concreto protendido, com $61 \%$ das obras do trecho estudado.

Conforme descreve Queiroz (2005), diversas obras foram e estão sendo executadas em estruturas de concreto protendido em diversos ramos da construção civil. Com as limitações do concreto armado a diversos fins, esta técnica 
apresenta uma solução econômica para os casos de estruturas que demandam grandes vãos ou em situações que necessitam diminuir os custos de manutenção das estruturas.

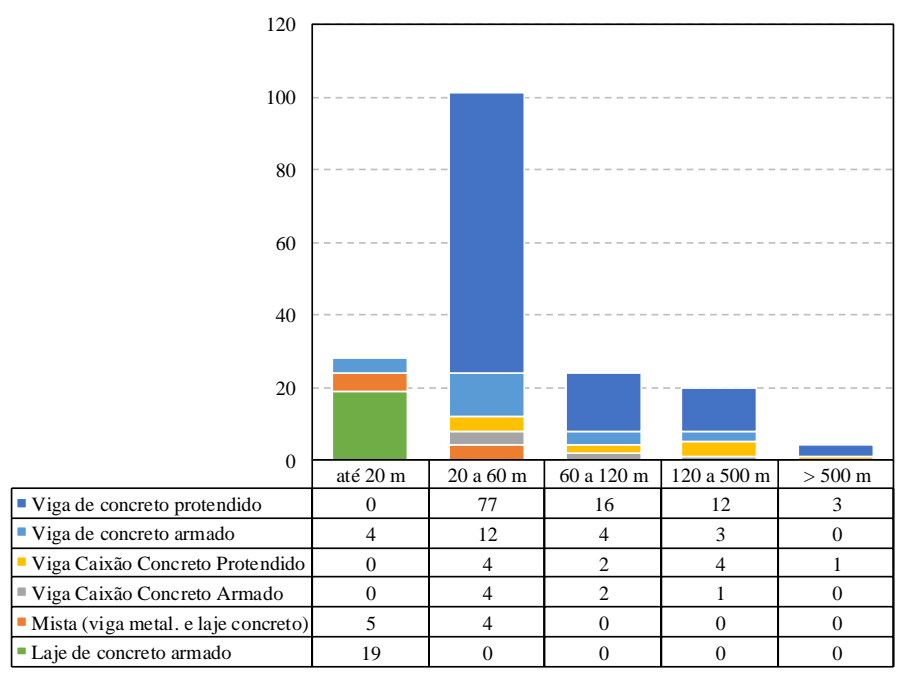

Figura 3: Relação de OAEs por faixa de extensão e tipos de estruturas

\subsection{DEFICIÊNCIAS FUNCIONAIS DAS OBRAS}

Nas inspeções foram estudadas várias deficiências funcionais, as quais são listadas na inspeção cadastral. Estas obras foram executadas da forma que se apresentam, por vários motivos, seja estes econômicos, culturais, necessidades diferentes da época, falha de projeto, entre outros motivos. Para as necessidades do tráfego atual, estas deficiências foram divididas em 24, conforme Figura 4. Nessa, são apresentadas todas as deficiências funcionais estudadas na BR101/SC, das quais 9 deficiências possíveis foram encontradas nas OAEs, totalizando um número igual a 188 deficiências, levando em conta que a maioria dessas estão em obras com notas técnicas inferiores a 3.

Na Figura 4 são apresentadas todas as deficiências funcionais estudadas na BR-101/SC, sendo elas 24 deficiências funcionais, das quais 9 estão presentes nas obras estudadas, tendo sido indicadas 188 vezes, considerando que muitas das obras apresentam várias deficiências.

No caso da deficiência funcional ponte estreita, em uma rodovia pode ser considerada quando a largura da pista for menos de 7,20 m. Neste horizonte de pesquisa, não foi encontrada nenhuma obra com este tipo de deficiência, por outro lado grande maioria têm largura ineficiente, pois 24 são sem acostamento. Outro ponto avaliado é em relação a largura do acostamento quando menor que $1,10 \mathrm{~m}$, onde $13 \%$ das estruturas do trecho estudado possuem essa deficiência caracterizando estreitamento ou ausência total do acostamento. Do total, 79 OAEs, quase metade do total, não possuem calçadas para pedestres, demostrando bem as características da época de sua construção, pois, muitas são da década de 70, e as obras de duplicação são do ano 2000. A deficiência quanto a drenagem das obras também se destaca com 21 das obras não apresentando pingadeira e 27 com marcas de acúmulo de água da chuva denotando drenagem de pista insuficiente.

Outras deficiências encontradas neste estudo foram 6 OAEs com trem tipo de cálculo TB 36tf, aparelho de apoio não identificado (quando não é possível visualizar o aparelho) em 22 estruturas, uma estrutura com viga caixão com interior inacessível, outra com junta longitudinal de dilatação e 7 obras com guarda-rodas obsoleto. Essas pontes com guarda rodas obsoleto em sua grande maioria apresentam necessidade de restauração da estrutura e, possivelmente, serão comtempladas com a troca deste elemento por barreiras New Jersey. 


\begin{tabular}{clc} 
Cód. & \multicolumn{1}{c}{ Deficiências Funcionais } & Quantidade \\
1 & Ponte estreita (larg pista < 7,20m) & 0 \\
2 & Ponte sem acostamento & 24 \\
3 & Calçada para pedestres inexistente & 79 \\
4 & Pingadeira inexistente & 21 \\
5 & Drenagem de pista insuficiente & 27 \\
6 & Guarda-rodas obsoleto & 7 \\
7 & Seção hidráulica (greide baixo) & 0 \\
8 & Seção hidráulica (ponte curta) & 0 \\
9 & Concordância vertical ruim & 0 \\
10 & Concordância horizontal ruim & 0 \\
11 & Capacidade de carga limitada & 0 \\
12 & Gabarito vertical sobre via urbana insuficiente & 0 \\
13 & Gabarito vertical sobre rodovia insuficiente & 0 \\
14 & Gabarito horizontal insuficiente & 0 \\
15 & Gabarito vertical de navegação insuficiente & 0 \\
16 & Gabarito vertical sobre ferrovia insuficiente & 0 \\
17 & Pilar em canal de navegação sem proteção & 0 \\
18 & Alça de acesso inadequada & 0 \\
19 & Ponte muito estreita (em mão única) & 0 \\
22 & Trem tipo de cálculo TB 24tf & 0 \\
23 & Trem tipo de cálculo TB 36tf & 6 \\
24 & Junta longitudinal de dilatação & 1 \\
25 & Viga caixão com interior inacessível & 1 \\
26 & Aparelho de apoio não identificado & 22 \\
& & 188 \\
& & SOMA \\
\hline
\end{tabular}

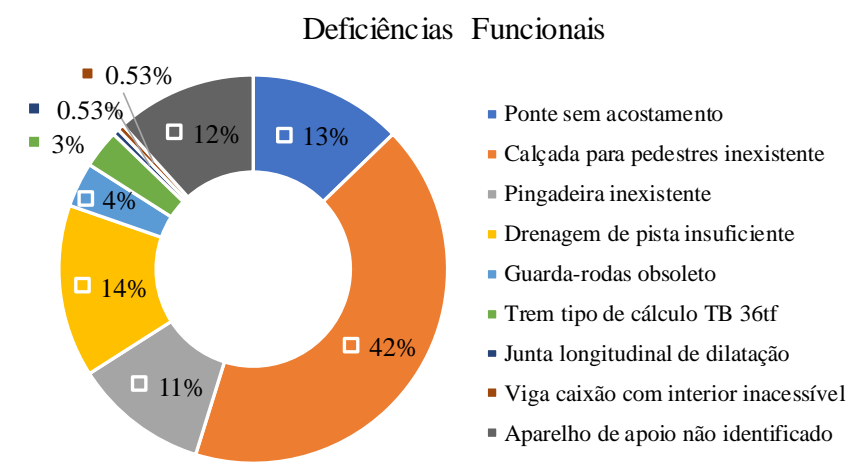

Figura 4: Deficiências funcionais nas OAEs

\subsection{INSUFICIÊNCIAS ESTRUTURAIS EM OAES}

Todo elemento estrutural que possui nota inferior ou igual a 3 e que participe da estabilidade da estrutura, deverá ter como correspondente uma insuficiência estrutural, segundo: Anexo C da Norma DNIT 010/2004-PRO.

Destas insuficiências, nas OAEs estudadas, $50 \%$ possuem trinca ou fissura de grande abertura ou armadura principal exposta e deteriorada, seguido por $20 \%$ com deterioração acentuada de materiais de construção e $15 \%$, mas não menos importante, apresentam ruptura do elemento. Vide Figura 5.

Quanto às outras insuficiências, quadro fissuratório intenso com $9 \%$ e perda ou comprometimento do apoio com $4 \%$ foram as com maior porcentagem subsequente, e por fim, com aproximadamente $2 \%$, o desconfinamento lateral em estaca de fundação, identificado em uma obra de grande proporção, o Viaduto km 409,75 (LE), com extensão de aproximadamente $2,5 \mathrm{~km}$. 


\begin{tabular}{clc}
\hline Cód. & \multicolumn{1}{c}{ Insuficiências Estruturais } & Quantidade \\
\hline 1 & Vibração ou impacto excessivo & 0 \\
2 & Deformação excessiva & 0 \\
3 & Deterioração acentuada dos materiais de construção & 11 \\
4 & Trinca ou fissura de grande abertura & 14 \\
5 & Quadro fissuratório intenso & 5 \\
6 & Recalque de apoio & 0 \\
7 & Perda ou comprometimento do apoio & 2 \\
8 & Ruptura do elemento & 8 \\
9 & Armadura principal exposta e deteriorada & 14 \\
10 & Armadura de protensão exposta e deteriorada & 0 \\
11 & Viga ou barra metálica principal com forte corrosão & 0 \\
12 & Conectores metálicos principais deteriorados & 0 \\
13 & Pilar com desaprumo acentuado & 0 \\
14 & Desconfinamento lateral em estaca de fundação & 1 \\
15 & Risco para o usuário & 0 \\
\hline & & 55 \\
\hline
\end{tabular}

Insuficiências Estruturais

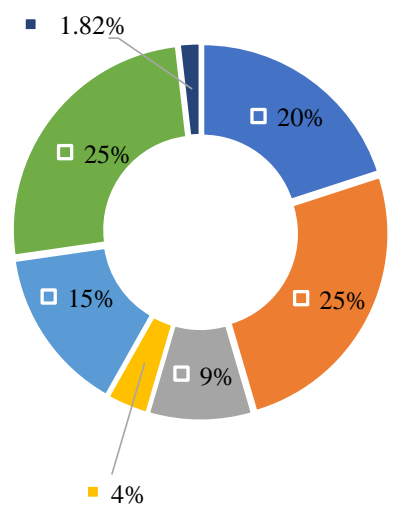

- Deterioração acentuada dos materiais de construção

- Trinca ou fissura de grande abertura

" Quadro fissuratório intenso

- Perda ou comprometimento do apoio

- Ruptura do elemento

- Armadura principal exposta e deteriorada

- Desconfinamento lateral em estaca de fundação

Figura 5: Insuficiências estruturais nas OAEs

\subsection{CLASSIFICAÇÃO DAS CONDIÇÕES DAS OAES}

As obras na BR-101/SC tem característica e estado de conservação muito semelhantes. Pode-se notar que a grande maioria delas estão em boas condições, necessitando apenas de inspeções rotineiras para acompanhamento de alguma alteração, tanto interna como externa.

Das 177 obras estudadas, nenhuma obra possui nota máxima. Por outro lado, 77\% das obras estão em bom estado de conservação (nota 4). As demais, tem-se $17 \%$ com nota 3, o que resulta em 30 obras. Essas obras inspiram maior cuidado, sendo necessário um acompanhamento anual para verificar alguma mudança brusca ou alteração no seu estado de conservação. Quanto as notas 2 e 1, é necessário um planejamento especifico, pois são obras que estão em condições precárias e problemáticas exigindo grande atenção. Neste estágio, deverá ser realizada uma inspeção especifica e programa-se a sua recuperação. Foram encontradas cerca de 7 obras, o que resulta em $4 \%$ das obras estudadas, com nota 2. Por último, as obras em estado crítico, que requerem cuidados imediatos, foram 3 obras, o que condiz com menos de $3 \%$ do universo estudado, conforme Figura 6.

\begin{tabular}{cc}
\hline Nota técnica & Quantidade \\
\hline 1 & 3 \\
2 & 7 \\
3 & 30 \\
4 & 137 \\
5 & 0 \\
\hline SOMA & 177 \\
\hline
\end{tabular}

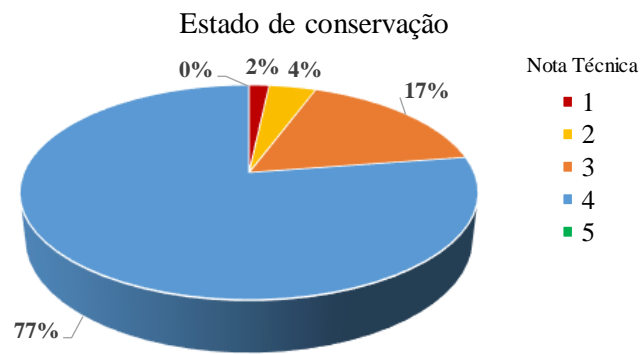

Figura 6: Classificação das OAEs a partir das notas técnicas

Muitas vezes, as manifestações patológicas são desencadeadas por ação de agentes externos, que causam, ou ajudam a causar, o início do surgimento de danos diversos. Vários destes agentes, nocivos às estruturas, em contato com a superfície causam degradação dos elementos componentes.

Em geral, os danos mais recorrentes nas OAEs são mancha de umidade, lixiviação e mancha de carbonatação, desplacamento do concreto, pavimento asfáltico danificado e nicho de concretagem. Na Tabela 2, é possível identificar os danos que mais estão presentes nas obras estudadas. 
Tabela 2: Relação de OAEs por tipos de estruturas

\begin{tabular}{cc}
\hline Danos nos elementos & Obras \\
\hline Manchas de umidade & 42 \\
Lixiviação e mancha de carbonatação & 31 \\
Desplacamento de concreto com armadura exposta & 29 \\
Pavimento asfáltico danificado & 26 \\
Nicho de concretagem & 17 \\
Manchas de fogo & 14 \\
Concreto desagregado com armadura exposta e oxidada & 14 \\
Fissura profunda fina & 14 \\
Junta danificada ou inexistente ou expelida & 14 \\
Fissura profunda aberta (w > 0,3 mm) & 12 \\
Infiltração no concreto & 11 \\
Erosão do talude de aterro & 6 \\
Rachadura ou trinca muito aberta & 5 \\
Berço para junta danificado & 4 \\
Aparelho de apoio danificado & 3 \\
Aparelho de apoio deslocado da posição & 3 \\
Armadura sem cobrimento & 3 \\
Fissura superficial & 3 \\
Buraco na pista (acesso) & 3 \\
Guarda-rodas ou barreira destruídos & 3 \\
Região com concreto esmagado ou rompido & 1 \\
Pavimento de concreto danificado & 1 \\
Fragmentação por fogo & 1 \\
Guarda-corpo destruído & 1 \\
Eerragem principal exposta em pontos localizadas & 1 \\
\hline
\end{tabular}

Quanto a ocorrência dos danos nas obras com notas 1, 2 e 3, pode-se observar que nas obras com nota 1 (Tabela 3), o dano mais presente é o dano "manchas de umidade". Porém, os danos como "fissura profunda fina", "fissura profunda aberta" e "ruptura do elemento", quando presentes em elementos que participam da estabilidade da estrutura, e quando superam os limites de abertura permitidos pela NBR 6118 (ABNT, 2014), são significantes para definir a nota técnica da OAE. Das três obras com nota técnica 1, duas apresentaram como sistema principal a viga de concreto protendido e a outra viga I metálica. No caso das OAEs com o sistema estrutural em protensão, a norma NBR 9452 (ABNT, 2016) determina que elementos protendidos principais fissurados apresentam nota técnica 1. Já para a outra OAE com nota técnica 1, o dano que caracterizou a nota indicada é dado pela ruptura do elemento da viga I metálica, provocado pela colisão de um veículo no local.

Tabela 3: Relação de danos nos elementos das OAEs com nota técnica 1

\begin{tabular}{ccc}
\hline Danos nos elementos & Qtde de elementos & Obras \\
\hline Lixiviação e mancha de carbonatação & 4 & 2 \\
Manchas de fogo & 1 & 1 \\
Manchas de umidade & 7 & 5 \\
Nicho de concretagem & 1 & 1 \\
Aparelho de apoio danificado & 1 & 1 \\
Desplacamento de concreto com armadura exposta & 1 & 1 \\
Pavimento asfáltico danificado & 2 & 2 \\
Junta danificada ou inexistente ou expelida & 1 & 2 \\
Fissura profunda fina & 2 & 1 \\
Fissura profunda aberta (w > 0,3 mm) & 1 & 1 \\
Ruptura do elemento & 1 & 2
\end{tabular}

No caso das obras com notas técnicas 2, é possível indicar na Tabela 4 os danos que mais foram encontrados nos elementos das OAEs. Observa-se que os danos estruturais classificados como desplacamento de concreto com armadura exposta e concreto desagregado com armadura exposta e oxidada foram os mais recorrentes. Os danos manchas de umidade e manchas de fogo com maior incidência não são considerados danos estruturais. 
Tabela 4: Relação de danos nos elementos das OAEs com nota técnica 2

\begin{tabular}{ccc}
\hline Danos nos elementos & Qtde de Elementos & Obras \\
\hline Manchas de umidade & 21 & 7 \\
Manchas de fogo & 7 & 4 \\
Desplacamento de concreto com armadura exposta & 10 & 4 \\
Concreto desagregado com armadura exposta e & 10 & 4 \\
oxidada & 3 & 3 \\
Lixiviação e mancha de carbonatação & 3 & 3 \\
Infiltração no concreto & 6 & 3 \\
Fissura profunda aberta (w > 0,3 mm) & 4 & 2 \\
Nicho de concretagem & 2 & 2 \\
Pavimento asfáltico danificado & 1 & 1 \\
Aparelho de apoio deslocado da posição & 1 & 1 \\
Região com concreto esmagado ou rompido & 2 & 1 \\
Fissura profunda fina & & \\
\hline
\end{tabular}

Nas obras com nota 3 (Tabela 5), as quais requerem uma menor ação imediata e sim, planejamento e acompanhamento, pode-se verificar que os danos são causados em sua grande maioria por causa de falta de uma drenagem eficiente na estrutura ou no pavimento, como por exemplo falta de pingadeiras. Pode-se notar que estes danos são relacionados com agentes externos comuns, como a água da chuva. Danos como manchas de umidade e lixiviação são os mais recorrentes nas estruturas. No caso dos elementos com nota técnica 3, 24 obras apresentaram desplacamento do concreto. Porém, segundo a NBR 9452 (ABNT, 2016), quando há anomalia na armadura principal exposta e corroída com perda de seção de até $20 \%$ do total da armadura, a nota técnica para o elemento principal é dita como 3 . No caso de anomalias no concreto, a nota técnica 3 é dada em elementos principais quando os mesmos apresentam concreto segregado em regiões de tensões de compressão em pequenas áreas.

Tabela 5: Relação de danos nos elementos das OAEs com nota técnica 3

\begin{tabular}{ccc}
\hline Dano nos elementos & Qtde de elementos & Obras \\
Manchas de umidade & 95 & 30 \\
Lixiviação e mancha de carbonatação & 43 & 26 \\
Desplacamento de concreto com armadura exposta & 18 & 24 \\
Pavimento asfáltico danificado & 22 & 22 \\
Nicho de concretagem & 27 & 14 \\
Junta danificada ou inexistente ou expelida & 14 & 13 \\
Fissura profunda fina & 15 & 12 \\
Concreto desagregado com armadura exposta e oxidada & 16 & 10 \\
Manchas de fogo & 14 & 9 \\
Infiltração no concreto & 8 & 8 \\
Fissura profunda aberta (w > 0,3 mm) & 11 & 8 \\
Erosão do talude de aterro & 6 & 6 \\
Rachadura ou trinca muito aberta & 5 & 5 \\
Berço para junta danificado & 4 & 4 \\
Armadura sem cobrimento & 3 & 3 \\
Fissura superficial & 4 & 3 \\
Buraco na pista (acesso) & 3 & 3 \\
Guarda-rodas ou barreira destruídos & 3 & 3 \\
Aparelho de apoio deslocado da posição & 2 & 2 \\
Aparelho de apoio danificado & 2 & 1 \\
Pavimento de concreto danificado & 1 & 1 \\
Fragmentação por fogo & 1 & 1 \\
Guarda-corpo destruído & 1 & 1 \\
Estaca desconfinada & 1 & 1 \\
\hline
\end{tabular}

\section{CONCLUSÕES E RECOMENDAÇÕES}

Conforme Heitner et al. (2019) o envelhecimento das infraestruturas no mundo moderno exige uma atenção especial de engenheiros e gerentes responsáveis para garantir adequados níveis de segurança e eficácia ao serviço público. Foi 


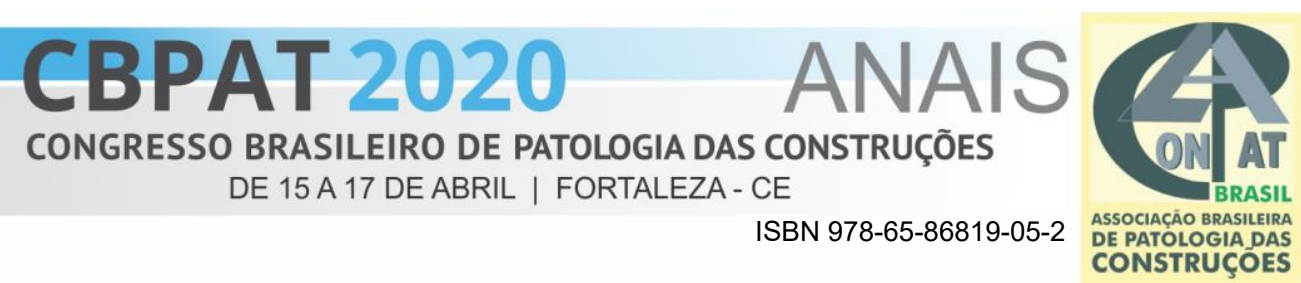

possível verificar neste estudo que as 177 obras estudadas possuem características bem parecidas, de acordo com a década de construção, e que a maioria das obras de arte especiais presentes na BR-101 de Santa Catarina foram executadas em vigas de concreto protendido.

Segundo Mei, Gül e Boay (2019), através de um monitoramento regular das OAEs, é possível se evitar perdas de vidas e bens monetários, assim como aumentar o tempo de vida útil da estrutura, e propiciando, desta forma, uma redução de custos de serviços, pois a manutenção é feita preventivamente e não quando a estrutura está em estado de criticidade. Conclui-se que as obras da BR-110/SC, em sua maior parte, estão em boas condições e as deficiências e insuficiências encontradas ainda não prejudicam a estabilidade das OAEs. Vale ressaltar que estas obras estão dentro de um programa de planejamento e monitoramento do DNIT, tornando possível um acompanhamento das evoluções das patologias encontradas. 


\section{REFERÊNCIAS}

AASHTO, 2007. MAINTENANCE MANUAL FOR ROADWAYS AND BRIDGES. AMERICAN ASSOCIATION OF STATE HIGHWAY AND TRANSPORTATION OFFICIALS. WASHINGTON D.C, USA. 379 P.

ABNT, NBR 9452, 2016: INSPEÇÃO DE PONTES, VIADUTOS E PASSARELAS DE CONCRETO PROCEDIMENTO. ASSOCIAÇÃO BRASILEIRA DE NORMAS TÉCNICAS. RIO DE JANEIRO, BRASIL. 48P.

DNER, 1996. MANUAL DE PROJETO DE OBRAS-DE-ARTE ESPECIAIS. DEPARTAMENTO NACIONAL DE ESTRADAS DE RODAGEM. MINISTÉRIO DOS TRANSPORTES. BRASIL. 233 P.

DNER, 1997. GLOSSÁRIO DE TERMOS TÉCNICOS RODOVIÁRIOS. INSTITUTO DE PESQUISAS RODOVIÁRIA. PUBLICAÇÃO IPR - 700.

DNIT (2004A). NORMA DNIT 010/2004 - PRO. INSPEÇÕES EM PONTES E VIADUTOS DE CONCRETO ARMADO E PROTENDIDO - PROCEDIMENTO. INSTITUTO DE PESQUISAS RODOVIÁRIAS. DEPARTAMENTO NACIONAL DE INFRAESTRUTURA DE TRANSPORTES. MINISTÉRIO DOS TRANSPORTES. BRASIL. 18P.

DNIT (2004B). MANUAL DE INSPEÇÃO DE PONTES RODOVIÁRIAS. INSTITUTO DE PESQUISAS RODOVIÁRIAS. PUBLICAÇÃO IPR - 709. DEPARTAMENTO NACIONAL DE INFRAESTRUTURA DE TRANSPORTES. MINISTÉRIO DOS TRANSPORTES. BRASIL. 255P.

DNIT, (2010A). MANUAL DE RECUPERAÇÃO DE PONTES E VIADUTOS RODOVIÁRIAS. INSTITUTO DE PESQUISAS RODOVIÁRIAS. PUBLICAÇÃO IPR - 744. DEPARTAMENTO NACIONAL DE INFRAESTRUTURA DE TRANSPORTES. MINISTÉRIO DE TRANSPORTES. BRASIL. 161 P.

FHWA, 2011. BRIDGE PRESERVATION GUIDE. FEDERAL HIGHWAY ADMINISTRATION. USA. 32 P. JB ON LINE, SITE PONTE, RV NOTÍCIAS - 2009.

HEITNER, B.; OBRIEN, E. J; YALAMAS, T.; SCHOEFS, F; LEAHY, C; DÉCATOIRE, R., 2019. UPDATING PROBABILITIES OF BRIDGE REINFORCEMENT CORROSION USING HEALTH MONITORING DATA. ENGINEERING STRUCTURES, ELSEVIER, V. 190, PP 41-51.

MEI, Q.; GÜL, M; BOAY, M.. 2019. INDIRECT HEALTH MONITORING OF BRIDGES USING MELFREQUENCY CEPSTRAL COEFFICIENTS AND PRINCIPAL COMPONENT ANALYSIS. ENGINEERING STRUCTURES, ELSEVIER, V. 119, PP 523-546.

QUEIROZ, W. L. R. (2005).MODELAGEM NUMÉRICA DE VIGAS PROTENDIDAS COM CABOS INTERNOS EEXTERNOS PELO PROGRAMA CARPE.DISSERTAÇÃO DE MESTRADO, PUBLICAÇÃO E.DM007A/05,DEPARTAMENTO DE ENGENHARIA CIVIL E AMBIENTAL, UNIVERSIDADE DE BRASÍLIA, BRASÍLIA, DF, 120P

VITÓRIO, A., 2002. PONTES RODOVIÁRIAS: FUNDAMENTOS, CONSERVAÇÃO E GESTÃO. CONSELHO REGIONAL DE ENGENHARIA, ARQUITETURA E AGRONOMIA DE PERNAMBUCO - CREA-PE. RECIFE. BRASIL. 85 P. 